\title{
A HISTORICAL TIMBER FRAME MODEL FOR DIAGNOSIS AND DOCUMENTATION BEFORE BUILDING RESTORATION
}

\author{
M. Koehl ${ }^{\text {a, }}$, A. Viale ${ }^{a}$, S. Reeb ${ }^{b}$ \\ ${ }^{a}$ Laboratoire ICube - UMR 7357, INSA de Strasbourg, F-67084 Strasbourg, France \\ (mathieu.koehl, anthony.viale)@insa-strasbourg.fr \\ ${ }^{\mathrm{b}}$ Communauté des Communes du Piémont de Barr, F-67142 Barr, France \\ sophie.reeb@pays-de-barr.fr
}

KEY WORDS: 3D modelling, virtual, 3D TLS, historical timber-framework, geometric model, GIS.

\begin{abstract}
:
The aim of the project that is described in this paper was to define a four-level timber frame survey mode of a historical building: the so-called "Andlau's Seigniory", Alsace, France. This historical building (domain) was built in the late XVI ${ }^{\text {th }}$ century and is now in a stage of renovation in order to become a heritage interpretation centre. The used measurement methods combine Total Station measurements, Photogrammetry and 3D Terrestrial Laser scanner. Different modelling workflows were tested and compared according to the data acquisition method, but also according to the characteristics of the reconstructed model in terms of accuracy and level of detail. 3D geometric modelling of the entire structure was performed including modelling the degree of detail adapted to the needs. The described 3D timber framework exists now in different versions, from a theoretical and geometrical one up to a very detailed one, in which measurements and evaluation of deformation by time are potentially allowed. The virtually generated models involving archaeologists, architects, historians and specialists in historical crafts, are intended to be used during the four stages of the project: (i) knowledge of the current state of needs for diagnosis and understanding of former construction techniques; (ii) preparation and evaluation of restoration steps; (iii) knowledge and documentation concerning the archaeological object; (iv) transmission and dissemination of knowledge through the implementation of museum animations. Among the generated models we can also find a documentation of the site in the form of virtual tours created from panoramic photographs before and during the restoration works. Finally, the timber framework model was structured and integrated into a 3D GIS, where the association of descriptive and complementary digital documents was possible. Both offer tools leading to the diagnosis, the understanding of the structure, knowledge dissemination, documentation and the creation of educational activities. The integration of these measurements in a historical information system will lead to the creation of an interactive model and the creation of a digital visual display unit for consultation. It will be offered to any public to understand interactively the art of constructing a Renaissance structure, with detailed photos, descriptive texts and graphics. The 3D digital model of the framework will be used directly in the interpretation path, within the space dedicated to "Seigniory" of Andlau. An interactive touch-screen will be installed. It will incorporate several levels of playgrounds (playful, evocative and teaching). In a virtual way, it will deal with the different stages of building a wooden framework and clarify the art of construction.
\end{abstract}

\section{INTRODUCTION}

\subsection{Study purpose}

The building that is subject of this study is located in Andlau, a small town of about 1850 residents located $40 \mathrm{~km}$ south of Strasbourg, Alsace, France.

1.1.1 History: The so-called "Seigniory" is a symbolic building of Andlau that is widely known in the region. This building was built in 1582 by one of Frederic d'Andlau's four sons. Andlau lords, vassals of the abbey, had several residences in the small town of Andlau.

This former mansion boasts the architecture in vogue at the end of the sixteenth century (Renaissance), materialized by polygonal tower hosting a spiral staircase. The property was the residence of the Counts of Andlau from the sixteenth century to the French Revolution (1789). The ground floor was occupied by the pantry and shops, the main floor by the main apartments, the second floor by the bedrooms, and the attic by vast granaries. The cellar was originally the tithe cellar. An attic for salt stood formerly on the south end of the property.

Formerly called "Red House" in relation to the name of one of the owners, Mr. Charles Rouge (Red in French) (1900), the building then took the generic denomination of Lordship ("Seigniory"). It is noteworthy that Mr. Charles Rouge, painter, collector and design theorist, turned his house into a museum, where he taught young people the art of drawing. He was also the author of a book: Drawing for All. In 1934, the facades of the main building were listed on the supplementary inventory of French historic monuments. The town of Andlau became the owner Seigniory in January 2005. The landscape and the geographical location significantly contribute to cultural development and have an influence on tourism in the center of Alsace. This place pregnant with history will soon host the Heritage Interpretation Centre (HIC), a lively place, open and accessible to all, valuing the heritage and knowledge of yesterday and today.

1.1.2 Works: The "Seigniory" is going to be completely restored to welcome the HIC. Besides, it will be endowed with a modern extension that will grant the reception of the public in optimal conditions. The ground-floor will be fitted out in a space dedicated to temporary exhibitions, both house floors and first level of the attic will be dedicated to the permanent exhibition (path of interpretation), the second level of the attic will host the administrative part and the last two levels will stay 
as they are and will not be accessible any more. Indeed, the works of restoration will tend to cover and to hide the largest part of the frame from view; the upper parts, very characteristic of the construction mode of the Renaissance, will not be accessible any more, nor visible for visitors.

Modelling will allow to maintain and visualize, and even to extract and measure frame's parts that cannot be more reached. Figures 1 (a, b, c, d) show some examples of interesting elements to be modelled and to be studied within the scope of this restoration: we find various types of assemblies and detect disorders.

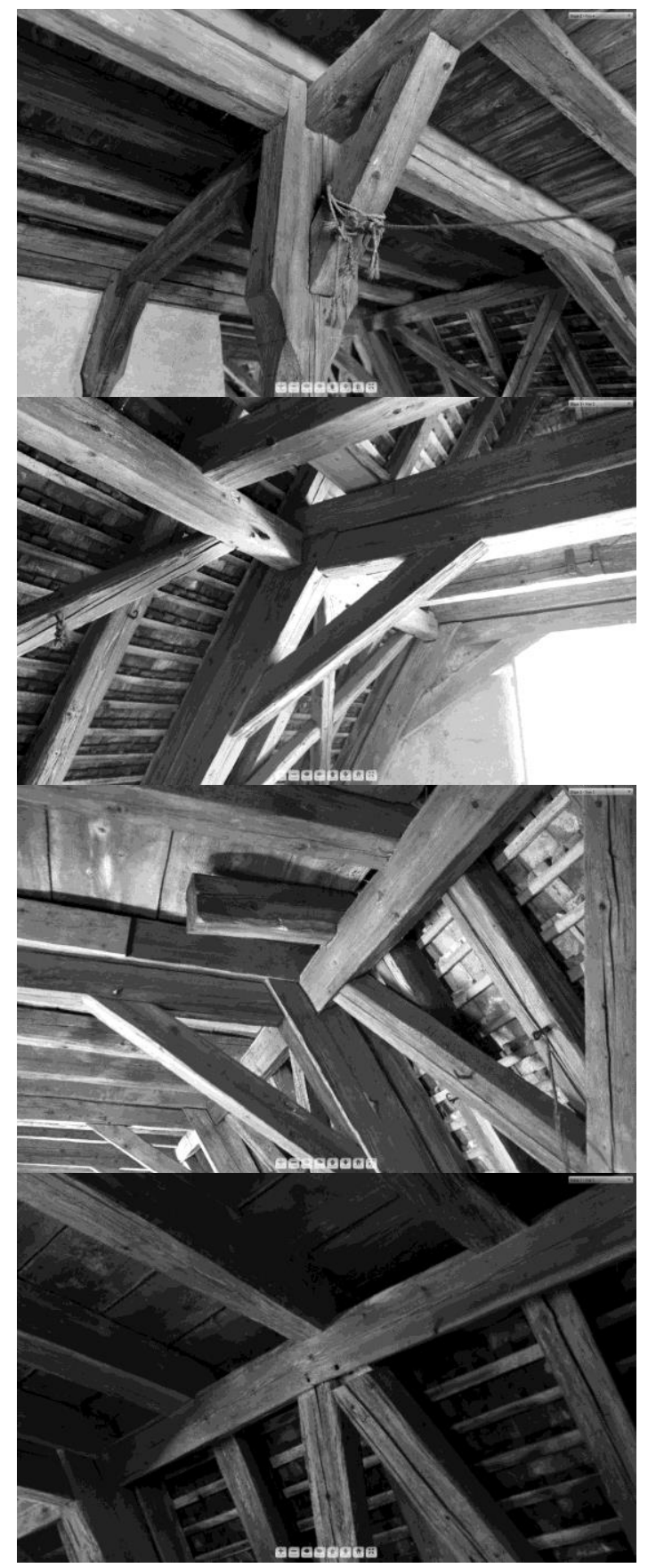

Figure 1.a, b, c: Framework assemblies, d: Assembly deformation

\subsection{Aim of the Study}

In this context a modelling of the structure is required to allow recording, to make diagnoses, to know and to consolidate the knowledge on this type of historic wooden frame. A virtual display will enable other applications, especially the provision of models for animations; it will also define the fundamentals of an Information System and supply the future HIC with digital data.

\subsection{The "Seigniory" of Andlau in Numbers}

- It was built in 1582 .

- It contains one ground floor, two other floors and four levels of attic of which the last one is not accessible.

- It is approximately $25.8 \mathrm{~m}$ long, $14.5 \mathrm{~m}$ wide and $23 \mathrm{~m}$ high.

- The frame contains approximately 600 wooden elements.

- The first level of the attic is $14.7 \mathrm{~m}$ in width for $24.7 \mathrm{~m}$ in length, which corresponds to a surface of about 363 square meters.

- $\quad$ The second level of the attic is $9.7 \mathrm{~m}$ in width for $24.7 \mathrm{~m}$ in length, which corresponds to a surface of about 240 square meters.

- The third level of the attic is $6.2 \mathrm{~m}$ in width for $24.7 \mathrm{~m}$ in length, which corresponds to a surface of about 153 square meters.

- The last level contains no special wooden frame structure.

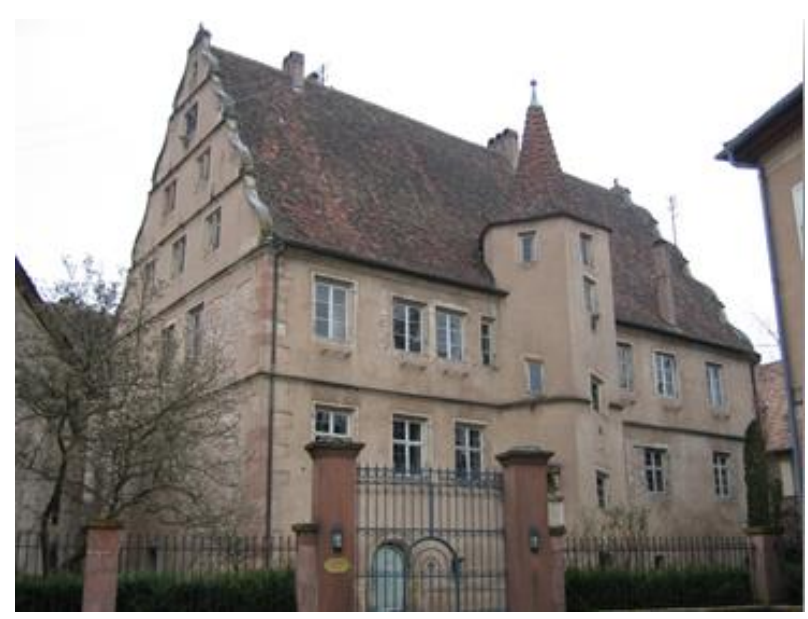

Figure 2.a: "Seigniory"

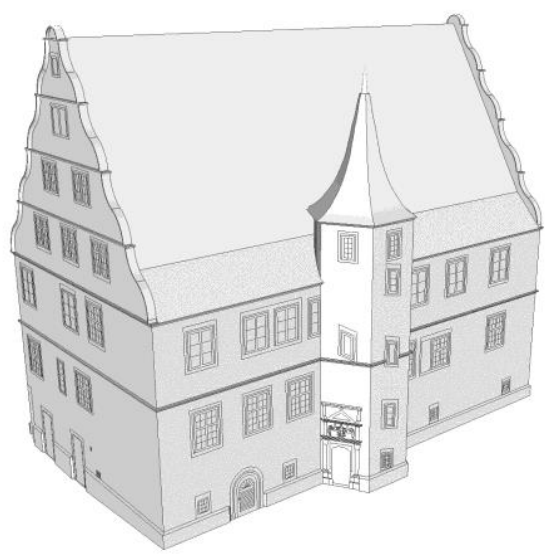

Figure 2.b: CAD model 


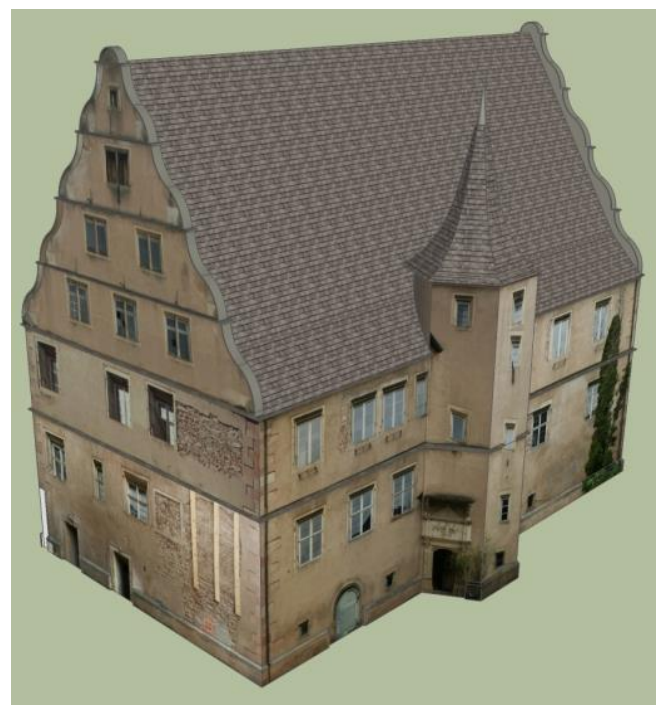

Figure 2.c: Textured CAD model

This article is structured in three parts. The first part presents state of the art research on the topic. It summarizes the definition and the role of a wood frame, the different components, their assemblies and their construction in the particular context of the "Seigniory". Then the various ways to represent the wooden elements will be explained: the techniques of 3D modelling, the creation of animations and the capture of panoramic photographs for the creation of a virtual tour.

The second part describes the work carried out, from the definition of the reference points to the different surveying techniques. It then summarizes the modelling methods based on point clouds, the criteria that have guided the choice of level of detail in the final 3D model. It ends with the description of recording and computing of panoramic photographs, which is the basis for the constitution of the virtual tour.

\section{STATE OF THE ART RESEARCH}

\subsection{Historical Wooden Frame}

Before undertaking any survey work or any modelling, one must first seek to define the frame, its type, its constituent parts, assemblies, its role and functions: in the case of Andlau's "Seigniory", it is a frame with common rafters without purlins. The assemblies of the various parts are not visible (only in some places where parts are dislocated, it is thus necessary to explore ways to fasten the assembly. Valentin (2008) explains that until the nineteenth century, all component parts of a frame were assembled by mortise and tenon joint type, all blocked by wooden pegs.

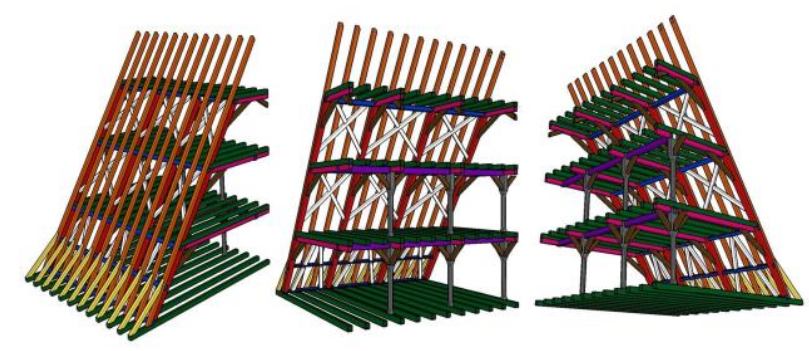

Figure 3: Structure of framework
The frame of the "Seigniory" follows this rule; there are right and oblique joints with mortise and tenon assemblies and special assemblies for long spans (beams, purlins). To understand the constitution, we referred to Figure 3 extracted from the final modelling.

\subsection{Modelling and Visualization of the Wooden Frame}

Modelling has several roles. It helps preserve and disseminate the data to share knowledge on the history of architecture, the relationship between materials by bypassing the language barrier (Huang et al., 2005). Heritage conservation is considered as an important issue in many countries and computer reconstructions are booming because they can capture the attention of the general public. They make easier the visualization of structures through virtual environments that allow the user to explore the buildings from all angles.

Today, 3D rendering software is very sophisticated and provide a high degree of realism: we can create light effects, shadows, mist, dust, etc. This enables to create photo-realistic scenes. In the case of a model, we must nevertheless draw the attention of the user to the areas of its uncertainty: the areas which are based on assumptions and not on actual measurements (Dawson et al., 2006).

Allowing the study of structures, some virtual reality software provide for the addition of objects' characteristics (mass, strength, elasticity, etc.) to give them real close behaviour. We can thus assess the stability of structures by loading them virtually. Research has to develop structure-evaluating methods thanks to 3D models and so look for areas that present a risk of collapse.

These diagnoses reveal important information for periodic maintenance, repair or structural alteration (Caarnaño et al., 2004) (Arias et al., 2005), (Lubowiecka et al., 2007).

They also enable anthropological studies and the knowledge of the old ways of life; archaeologists can demonstrate a relationship between architecture and culture. By studying the volume of interior space thanks to virtual reality, one can find where people sat, stood, met, etc.

By creating a light source reproducing the sunlight, one can simulate the illuminated areas and estimate places that allowed performing tasks that required good lighting or even find the theoretical position of artificial light sources. The 3D models are powerful research tools to test different scenarios and to learn more about our ancestors.

The creation of models whose objective is defined in the framework of geometric, spatial, and temporal knowledge implies taking a complex approach to analysis and organization of information, which frequently are left out of the normal survey applications. Knowledge also proceeds by subsequent accumulations of information which are built up in a unique container that must make it possible to use them, analyse them and provide interrelationships that can be traced, plus an opportunity to extract the appropriate knowledge. The database offered by the geo-referenced point clouds represents the Spatial Information System for architecture (Gianninetto et al., 2006) which can be used to base important assessments for classifying structural elements or determining the state of decay or conservation of every element that composes the object of study (Fregonese et al., 2009).

(Lourenço et al., 2001) examines the main types of floor found in Italian historical buildings and analyses their deterioration and failure. The various aspects of current restoration interventions were examined, by comparing innovative as well as traditional techniques. The paper ends with a case study, which is deemed exemplary for diagnostic purposes (geometric 
measurements, constructive elements, visual investigations of materials, resistance measurements, thematic maps relative to the state of preservation of the material, flaws, deterioration and instability), illustrating the subsequent rehabilitation interventions, which implement alternative solutions in terms of "non visibility" and "retract ability" of the intervention.

\subsection{Data Acquisition Methods and Modelling Process}

3D scanners provide very good results in terms of data recording. They acquire point clouds, but for a more geometric representation, we must define a modelling procedure. This process can be lengthy and costly (ratio of one to ten). We needed to develop a method to detect automatically the wooden parts of the structure (Ling et al., 2007). Different data sources corresponding with different modelling approaches can be used. For a large number of relatively regular wooden components, traditional surveying approaches can meet the requirements. In this task, co-planarity of four points (or above four) and sampling frequencies must be considered carefully. For the irregular geometrical structure, digital photogrammetry or laser scanning technology can be used. Development of laser range finding technology represented by laser scanning technology provides human beings with brand-new technological means in obtaining spatial information. Laser scanner can automatically finish its work in attaining point clouds consisting of discrete points on the surface of the object. Points can be joined in different ways so the main work for 3D model reconstruction is to extract characteristic points, based on which characteristic lines and surfaces have to be constructed, A lot of manual operation is in need since automation level is not that high at present.

Photogrammetry is less expensive and can also create 3D models. Its advantage, as laser scanning, consists of remaining a non-contact method. For 3D modelling by means of 3D close range photogrammetry (Du et al., 2005), the general workflow includes four steps: data preparation, data processing, data organization and visualization. Obtaining CAD reference models by traditional surveying approaches and collecting relative information are the main tasks in the process of data preparation. Man-machine modelling, from CAD reference models to detailed textured models is the longest process in the workflow. For (Arias et al, 2007) photogrammetry can be used as a non-destructive tool to give precise $3 \mathrm{D}$ information about the size and shape of some elements of a structure, quickly and with no risk to the surveyors. On the one hand, photogrammetry makes it possible to obtain precise 3D models of highly irregular elements, as old timber purlins and trusses in the case of ancient constructions; on the other, photogrammetry is a noncontact method that minimizes the measurement time and allows to obtain the section properties, which can be used together with some material testing characterization to evaluate the structural safety of the construction. In (Fregonese and Taffurelli, 2009), the primary and secondary wooden beams were realized through the use of primitives, with automatic generation of solids or patches of the point cloud, thanks to the use of best fitting algorithms of the spatial surfaces. This procedure has led to simplification of the complexities that characterize these elements, made up of a "living" material such as wood, distinguished by defects or deformations and twisting induced by the static behaviour of the structure as a whole. Where the deviations of the real geometry of the surface were considered acceptable, the process was conducted in the semiautomatic mode, working in the Cyclone environment, while in the other cases, modelling was done in CAD (Autocad 2008 Cloudworx 3.2), through the use of cross-section profiles along the directions chosen. At least (Blersch et al., 2006) proposed, in order to arrive at a completely meshed model by triangulation the point cloud to divide in parts, due to the logical morphology of the object, cutting through the small sections of the short corridors. During the single meshing operations a couple of uncovered fields, like back face areas of the objects, had to be integrated by homogenous point grids which were generated with Rhinoceros software. For the gathering process of the meshed units occurred an intelligent decimation of the flat areas to $60 \%$. After gathering the units got sewed and then an overall decimation to $80 \%$ was applied in order to flatten the joints and to arrive at a handy model. During the modelling process, carried out with the software RapidForm, the operator had to create straight surfaces by intelligent choice of anchor points identifying every single carpentry member and its logical deformation property to load conditions in order to orientate the straight surface on its restraints using a pondered average and not on intermediate and eventually flexed parts (arithmetic average). In this way all flexing carpentry members would result curving below the ideal (straight) carpentry members and therefore give a homogenous global overview. An average position of three points per short edge was chosen (six points per surface) in order to avoid wrong orientation of the straight surfaces on single conditioned anchor points.

The third way is to use knowledge of construction to rebuild a model; collaboration between archaeologists and computer specialists is here needed.

To reduce the point cloud processing time, a method for the automation of the modelling was introduced. The idea is to create a set of rules based on architectural knowledge to automate the reconstruction.

The method "rule-based modelling" is based on four rules:

- The form rule,

- The size rule,

- The position rule,

- The linkage rule.

From the point cloud, using different types of constraints (rotations, translations, etc.) corresponding to the four previous rules, it is possible to automate the modelling of each beam.

\subsection{Animations}

(Haddlesey, R., 2005) has been researching different ways of viewing a frame. He developed methods to display data in $2 \mathrm{D}$ and $3 \mathrm{D}$ in order to disseminate both visual and textual results. $\mathrm{He}$ studied the evolution of timber structures in southern England in the period from 1400 to 1530 . He maintained that to study buildings, the third dimension is needed to advance the understanding of structures such as frames. Actually, many archaeologists and architects working on the buildings face a major problem in using traditional methods such as 2D drawings. They are obliged to multiply the number of documents, and information is in this case difficult to analyse and exchange. They cannot take full advantage of the data. The contribution of the third dimension can provide new information such as spatial relations, stratigraphy, and especially an easy way to read data.

\subsection{Panorama}

A panorama is an image-format extension to a wide horizontal field, often conducted in medium or large format (Chéhu, 2003). To create panoramas there are mainly three methods: image capture without rotation, image capture with rotation and assembling panned images. 


\subsubsection{Image Capture without Rotation:}

To create a panorama we can crop an image in a conventional wide screen. There are also orthoscopic cameras, that have a panoramic field and a film format that doesn't require any trimming.

2.5.2. Image Capture with Rotation: There are two main families of rotating cameras; those with a rotating objective and those with a rotating camera box. The former are composed of a turret which supports the photographic lens. A slit placed at the rear of the lens exposes the film during the rotation (Chéhu, 2003). For the latter, the camera box turns on itself at $360^{\circ}$ and has the same speed as the film (Frich, 2004).

2.5.3. Assembled Panorama: Recently, assembled panoramic photo software has revolutionized the practice. The use of a conventional digital camera is sufficient to achieve results previously reserved for owners of expensive components. This method will be detailed below because it is advantageously used for the project.

The shooting is to be taken by assembling a series of photographs with minimal recovery (25 to $30 \%$ ) to enable the processing software to combine pictures into one panorama. To use this method, it is necessary to have a digital camera if possible with a manual exposure mode, an effective sunshade on the lens and a minimum resolution of 2 megapixels. A tripod and a panoramic head device to eliminate any parallax between two photographs; perfect connections are also part of a professional equipment. The panoramic head Manfrotto 303, $303+$ or $303 \mathrm{SPH}$ allows thanks to its notching placing the unit in a same position, allowing taking photographs again with different settings. It is essential to make use of a leveling unit so that the camera remains horizontal during rotation, in order to avoid a cropping of the photographs (Frich, 2004).

The important steps in achieving a picture by assembling are given by (Frich, 2013):

- choose a frame and the final angle of the photo;

- set up the tripod and use a horizontal level unit;

- put a camera perpendicular to the ground;

- measuring light and contrast differences;

- make the shot;

- retouch images;

- carry out the assembly with a program like Autopano Pro (Kolor, 2013), Stitcher (Autodesk, 2013), ImageAssembler (Panavue, 2013) or Panorama Factory (PanoramaFactory, 2013), Hugin (2012), etc.

\subsection{Virtual Tours}

A virtual tour is composed of one or more panoramic photographs covering a field angle of up to $360^{\circ} \times 180^{\circ}$, that is to say a complete sphere. In general three main formats of virtual tours, each corresponding to a viewer are used:

- Flash: This format is universal, it is integrated in web browsers, is available on Windows, Mac and Linux. Most websites use it, so it is installed on most computers.

- Java: This format is the oldest of the three, it is also very light. It is found on Windows, Mac and Linux but also on some mobile phones. Like Flash, many sites also use it; its installation is less systematic.

- Quicktime: this format is one of the most famous ones in the virtual reality world.

\section{ACQUISITION AND DATA PROCESSING}

\subsection{Data Acquisition}

The fieldwork was done in three main parts: $\mathrm{i} /$ the establishment of network of reference points for automatic point clouds georeferencing, ii/ the various TLS point cloud acquisitions in the four attic levels and finally iii/ the shooting of images to perform the panoramic virtual tour.

\subsection{TLS Acquisition}

The point clouds were recorded with a "Trimble GX" TLS and partly with a "Trimble $C X$ ". The characteristics of the scanners can be found in (GIM international, 2010). The 3D scanner "Trimble $G X$ " has characteristics that are not optimal for the type of survey conducted. Its performance in both speed of acquisition and minimum distance, required selection and adaptation of the measurement method to the instrument. "Trimble $C X$ " has a significant advantage because of its field of view that eliminates blind spots at the zenith, which is particularly useful in our type of project. Its measuring process has to be available including information on the beams located at the vertical of the instrument. The largest vertical field of view was even more necessary for the measurements of the last level. Its occasional use has yielded interesting results.

Direct geo-referencing was made thanks to the reference points measured in the first step. The mean accuracy obtained after setting up scanner station was $+/-1 \mathrm{~cm}$. The environment of the attic with wood flooring does not ensure a better quality of scanner setting up and measurements.

The parameters of "Trimble GX" were set to acquire point clouds with a spatial resolution of about $1 \mathrm{~cm}$ at $5 \mathrm{~m}$. The recovery of individual point clouds increased the density of the full point cloud once merged, and thus, the resolution. With "Trimble CX", much faster, the space resolution was reduced to $5 \mathrm{~mm}$ at $5 \mathrm{~m}$ while maintaining a much shorter acquisition time (7 minutes for a full turn).

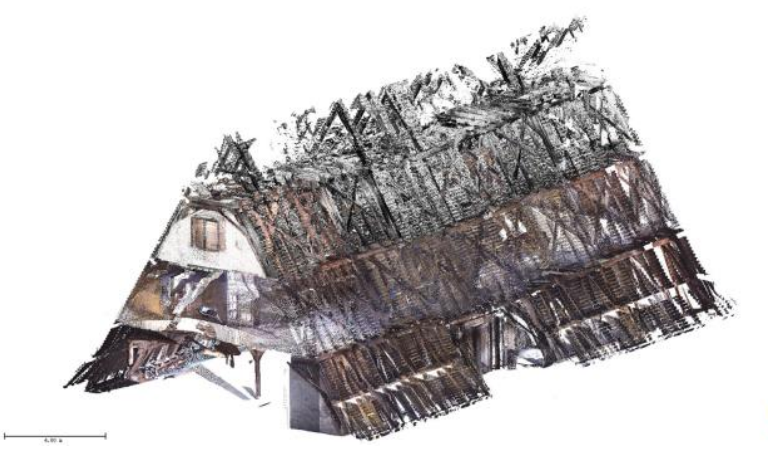

Figure 4: Merged point clouds

Scanners stations were chosen to cover the entire frame. There were:

- 7 stations for the first level, about 18.5 million of points and $8 \mathrm{~h} 30$ of cumulative measurement time,

- 6 stations in the second level, about 7 million of points and $4 \mathrm{~h} 15$ of cumulative measurement time,

- 6 stations ( 2 with the "Trimble GX" and 4 with the "Trimble $C X$ ”) for the third level, about 95 million of points and one hour of measurements.

Figure 4 gives an overview of the combination of all the point clouds during the various campaigns. 


\subsection{Photogrammetric Surveys}

The equipment used for image capture was composed of:

- A digital camera Canon EOS 5D type SLR

- A digital camera Sony Bridge H5O

- A tripod.

Images were taken to model briefly the outside of the "Seigniory". The PhotoModeler software was used to model and texture the 3D model.

This survey method was also tested on the frame. Lighting facilities were established to easily materialize this stage. Ramps of neon tubes were arranged on both sides of each photographed area. With this method, geo-referencing is harder than with a 3D scanner and above all, it is difficult to control field data acquisition; this can be considered as the disadvantages of such a method.

\subsection{Total Station Survey}

Another method coming from conventional survey was also tested in this study. The beams were identified through a total station (Leica "TSO2" Total Station), taking measurements on the ends and edges of them.

Compared to the point clouds acquired by 3D scanner, the number of data is very low but the points are all significant. An exhaustive survey is much longer as with a $3 \mathrm{D}$ scanner and the necessarily limited number of measured points does not allow a detailed study of the structure. While it is still easy to find the beams having no distortion, those which are deformed over time are more problematic and need a multiplication of measures. Lighting is also very delicate, and therefore it remains difficult for the operator to identify correctly the end of the beams, which can be a source of error.

The advantage of this method is that it is possible to codify the measures and thus automate, subsequent processing to CAD drawing. This feature is not included in the 3D scanner measures. While time is long on field measurement, processing time is much shorter.

This method is recommended for a brief survey of the structure, which is not the case here. Since the structure will be changed soon, the method providing a maximum data of the current state was preferred. This data can constitute interesting archives. They can be processed afterwards if necessary, and retrieving information can be essential when they are not even more visible, nor accessible. The choice of using a TLS finds here a good justification in the context of this study.

\subsection{Panoramic Image Capture}

The material used for the panoramic shots was:

- A camera Canon EOS 5D, type SLR,

- A spherical panoramic head Manfrotto 303+,

- A tripod.

During the study, a new opportunity that was not originally planned to see the structure was tested: the virtual tour from panoramic photographs. The formation of an assembled panoramic photograph requires a large number of photos using a spherical panorama head. In general we must ensure an overlap between photographs of about $30 \%$ minimum and we cannot use photographs with too pronounced contrasts differences. But with the environmental conditions in the attic (lighting difficulties) we used recoveries of approximately 50 $\%$. So it was easier to rectify underexposed or overexposed photographs and also to focus on different focal planes in the final panoramic photo. The assembly and photo rectification was performed on the Autopano Giga software.

The positions of different points of view were chosen according to several criteria:

- to ensure the inter-visibility between adjacent positions,

- to link lower and upper level at each level in the panoramic tour,

- outside, it is necessary to view the "Seigniory" from different angles and in its environment.

By following these criteria, the virtual tour created allows the user to move from one point of view to another one, as he would do naturally in the real world.

Each picture was taken with a gap of $24^{\circ}$ horizontally with approximately $50 \%$ overlap and with a lens focal length of 24 $\mathrm{mm}$. That means 15 photos to cover $360^{\circ}$. A complete panoramic photograph requires in this case 5 series of 15 photographs taken with vertical angles of $-30^{\circ}, 0^{\circ},+30^{\circ}$ and $+60^{\circ}$, then one last image at $+90^{\circ}$. This brings us to a total of 61 photographs.

\section{MODELLING}

The aim of the study is to provide a $3 \mathrm{D}$ model to create a scenography and interactive content that can be integrated in an interactive terminal. This teaching aid will allow the public to visualize the structure, manipulate the model and explore the construction and the different parts of the framework. It will also supply professionals, experts, historians and archaeologists with the framework model that is no longer fully accessible.

The unrefined point clouds cannot be directly used for this application. Therefore, from the data it provides, we have to create a workable model. Several parameters are to be taken into account:

- the level of detail in the 3D model;

- the time to model all the beams (the frame is composed of approximately 600 wooden pieces);

- the final file size on which its ease of handling depends;

- the format of the final file which also determines its interoperability;

- the choice of the texture applied (actual, generic, mean).

\subsection{First Approach}

The first approach starts from a point cloud to generate and reconstruct a $3 \mathrm{D}$ model.

The point cloud has two main shortcomings:

- At the rear of the beams, the point cloud is not very proper, which makes it difficult for positioning the angle. We need to segment the cloud to remove this effect before any treatment, in order not to generate errors. The clouds were geo-referenced with an accuracy of $1 \mathrm{~cm}$. In some areas where two scans overlap, shifts were observed. These drawbacks can be corrected by appropriate methods of consolidation.

To test the model, the point cloud of the first level was completely segmented, beam by beam in Trimble RealWorks (Trimble Realworks, 2013) software package. The idea is to implement a processing procedure in accordance with the five criteria seen above.

The starting object, common to all methods, is a point cloud corresponding to a beam of size: 3.26 in length with a section of 0.14 by 0.17 meters. The sizes of output files were compared by using a common Autodesk DXF file format.

Eight methods were developed and tested:

- Use of a simple mesh without filtration; 


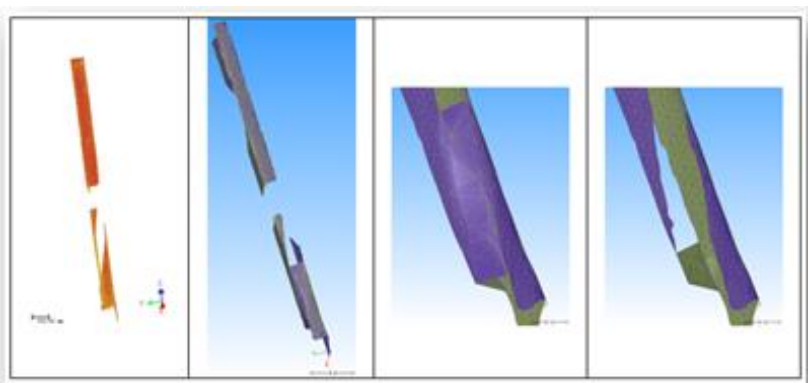

Figure 5a: Polygon meshes from point clouds with errors and removal of wrong triangles

- Extraction of cross-sections and networking between these sections;

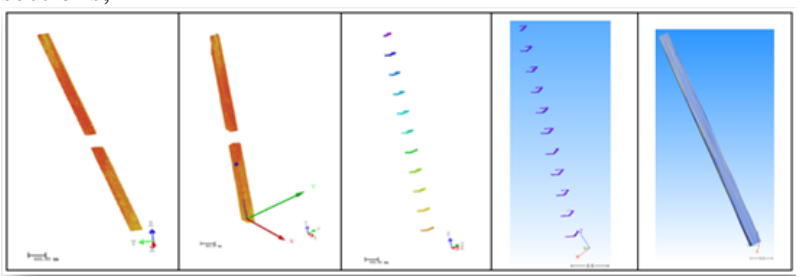

Figure 5b: Manual profile extraction and polygon meshes

- Extraction of cross-sections and calculation of mean planes between each profile (Figure 5c);

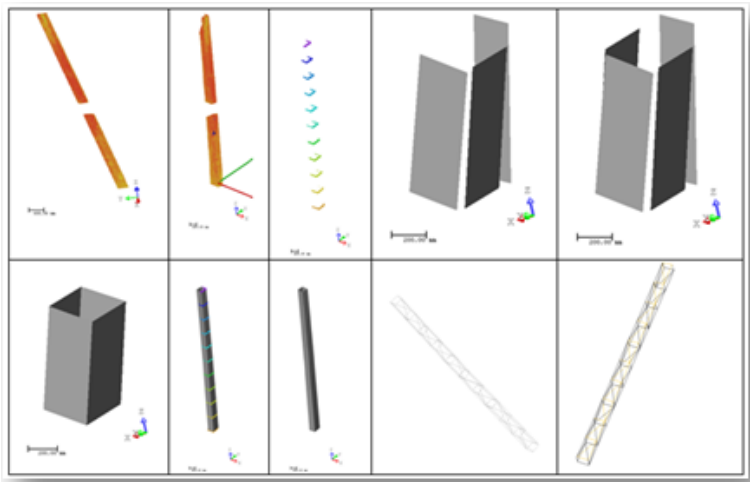

Figure 5c: Profiles and planar faces

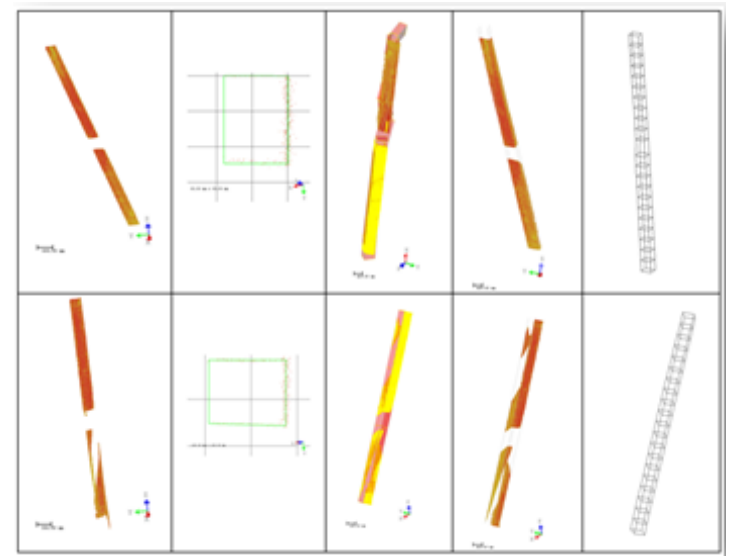

Figure 5d: Easy profile tool

- Use of "EasyProfile Tool" included in Realworks modelling tools that automatically generated a beam extruded from an average and automatically determined profile (Figure 5d);

- Method of the four plans representing a beam as four medium plans (Figure 5e);
- Method of extrusion from the longitudinal or main face of a beam (Figure 5f);

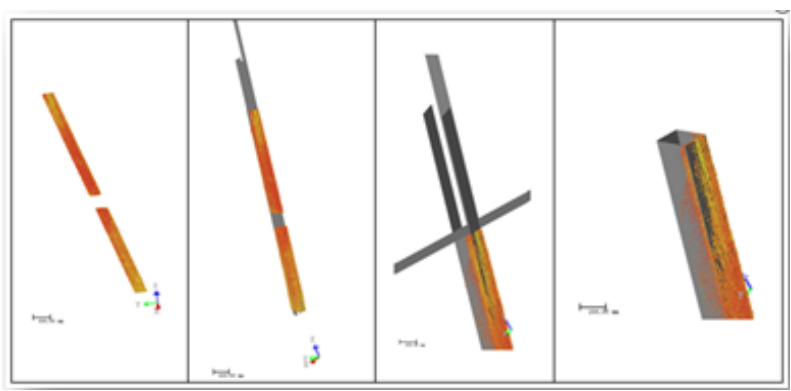

Figure 5e : Four planes model

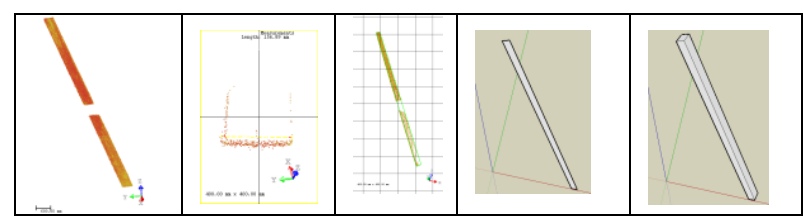

Figure 5f: Reference face extruded model

- Method of calculation in Matlab (Mathworks, 2012) to take into account local deformations and their integration in a very detailed model (Figure 5g)

- PhotoModeler (Photomodeler, 2013): use of software for multi-images photogrammetric restitution. These methods were described in (Koehl et al., 2010). They enabled the generation of beams at different levels of detail and different degrees of fineness. These methods were then compared according to the following six criteria.

The criteria compared were:

- Processing time;

- Degree of processing automation;

- Size of processed output file;

- Level of detail, depending on the fineness of the expected results;

- Importance of manual corrections necessitated after automatic processing;

- Management of missing faces.

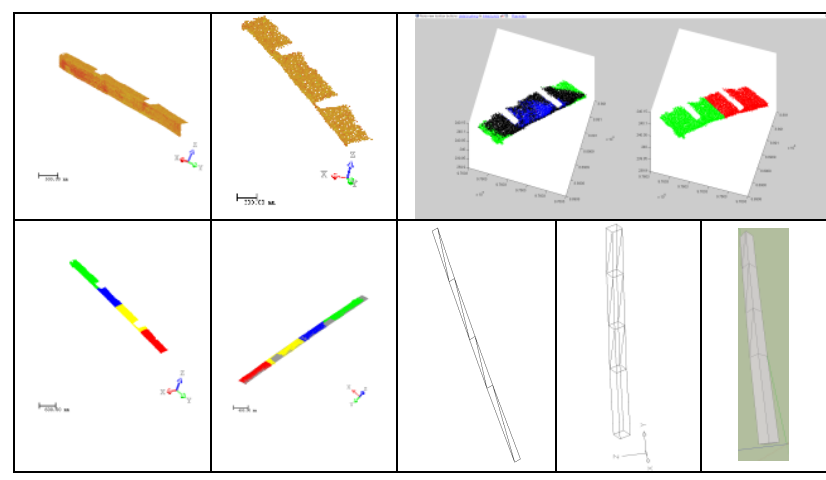

Figure 5g: "Matlab" processing

With the background of these obtained results, the project leader for the establishment of the HIC considered that a model that is as simple as possible was enough: the first goal of the model was to be didactic, to be able to acquaint users with the overall shape of the frame of the "Seigniory" and allow them to manipulate, disassembling and reassembling it interactively. 
Thus, the searched model is not necessarily a model of a high accuracy with a high level of detail.

For diagnostic work and in order to understand the evolution of the structure, specific and accurate models of parts of the structure may be ordered.

\subsection{Second Approach}

An approach completely opposite to the first one was then implemented. The principle for modelling the structure was based on knowledge and adaptation to measurements. From a first model that could be considered as theory, adaptation and enrichment by providing details were processed.

Most 3D models were created from this knowledge and some measurements. In principle, the main rafters have all the same size, like all the other beams that compose the frame. In a simplified model, there is no need to build each rafter with actual measurements that differ from others only in a few millimetres.

But the point clouds from 3D scans do not lose their utility. Dimensional measurements can be taken at any place within the framework and especially without coming back to the field. This approach also allows to evaluate the consistency of the produced models and, if necessary, to search for some details. The model contains the full measurements of the frame which is archived and can be accessed at any time.

The software used for the establishment of this model is the Trimble SketchUp (Trimble Sketchup, 2013) package. It actually contains many features that give genuine arguments in its favor.

Some of the admitted benefits are:

- creation of volumes and 3D objects with an efficient and intuitive extrusion tool;

- easily texture adding (real or generic);

- scenes composing, videos, animation generating and interactive modelling;

- management rendering (textured model, transparent model, wireframe model, color coded model, etc;

- management of Ruby scripts development of new features and analyses.

Figure 6 shows the stages of modelling in Trimble SketchUp.

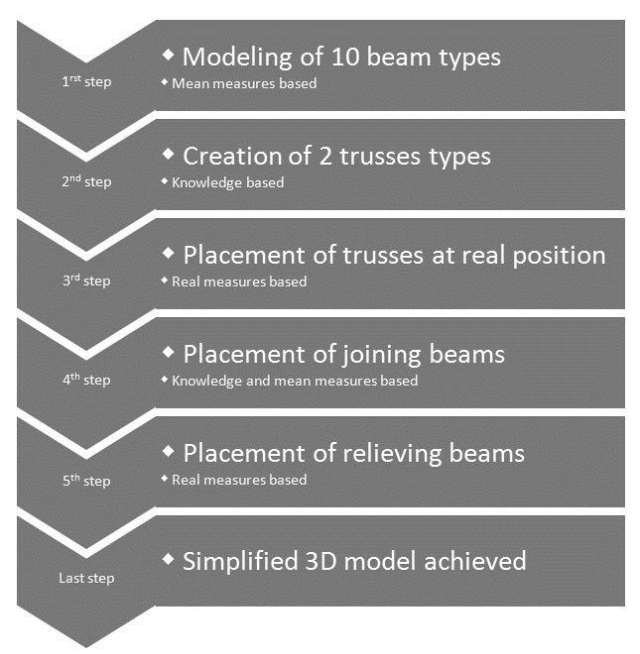

Figure 6: Modelling process in Trimble Sketchup

The first step is to model each type of beam. We listed 10 beam types and each type was structured as a layer and a colour code. Several pieces of each type were measured to determine average sizes. Discrepancies (inferior to centimetre) confirmed the validity of our reasoning.

Some beams were different from their counterparts. For example, the ends of the relieving beam of the third level were different from those of the second level because the main beams located above are not oriented in the same way. All elements of a piece of wood (lines and faces) were finally merged in a beam object.

The second step is to combine all the parts of the framework components. To follow the real case assembly reasoning, we had first to assemble the trusses (Figures 7).

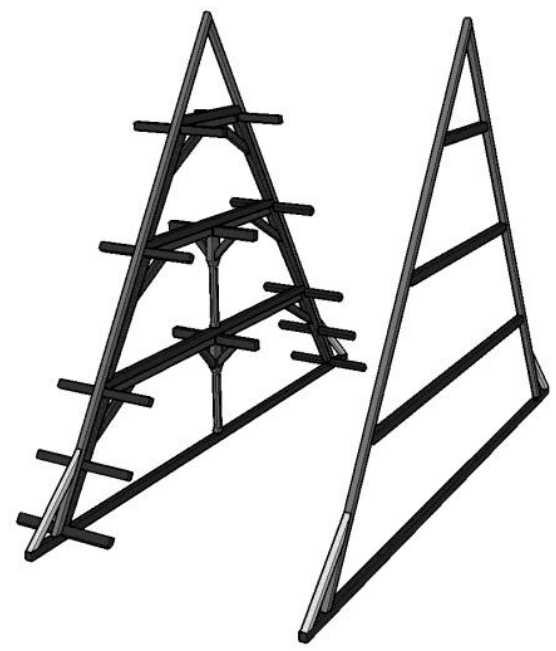

Figure 7a: Establishment of a truss

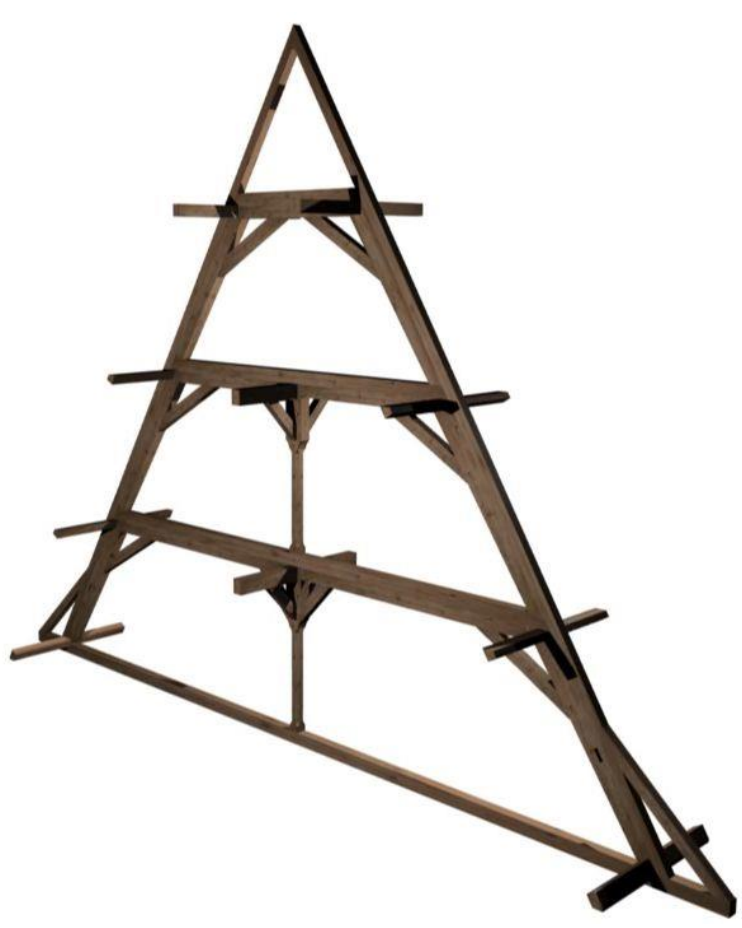

Figure 7b: Model of textured truss

The third step is to evaluate the average spacing between trusses. Here the measured values showed that the structure was 
not regular, the differences were relatively large: the spacing ranged between 44 and 66 centimetres.

The last step concerns the relieving beams that were different at each level. They all had a different position and finally each position was located to adapt the model to reality.

The fourth step defined the position of two beams and the ten main beams, the positions that had already been defined during the modelling of the strut and length depending on the total length of the frame.

The last step concerns the relieving beams that were different at each level. They all had a different position and finally each position was located to adapt the model to reality.

This modelling process is exposed in Figure 8.
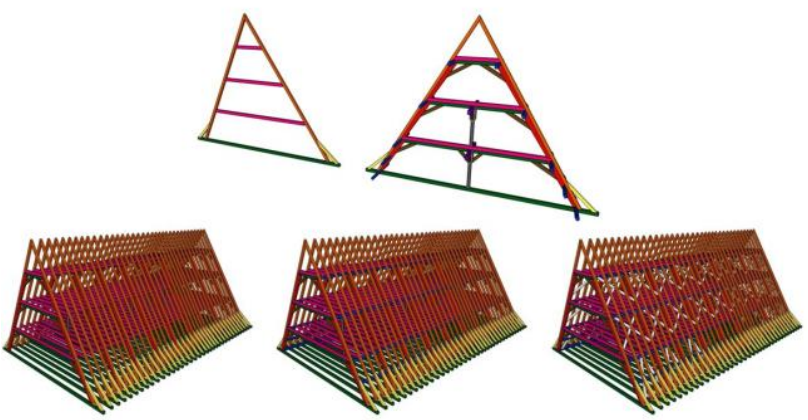

Figure 8: Modelling process

Figures 9 show results obtained as a complete frame.

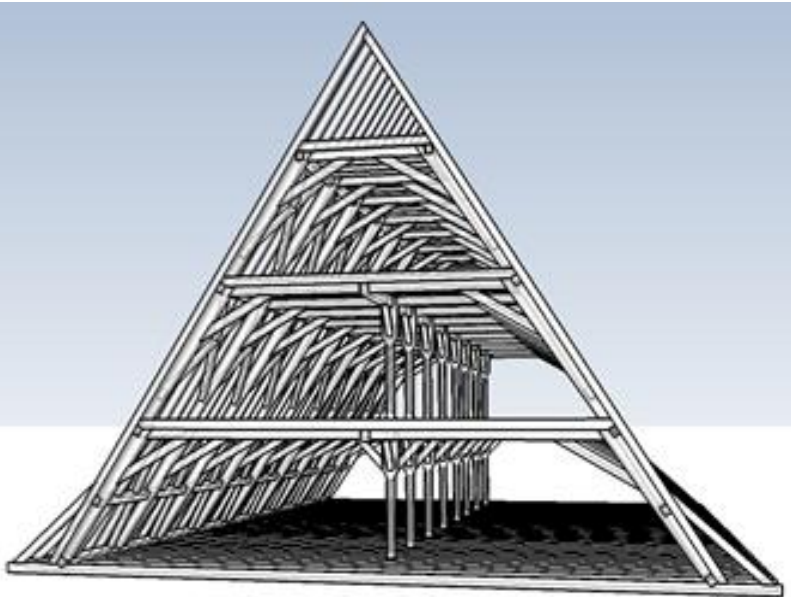

Figure 9a: Model of full framework

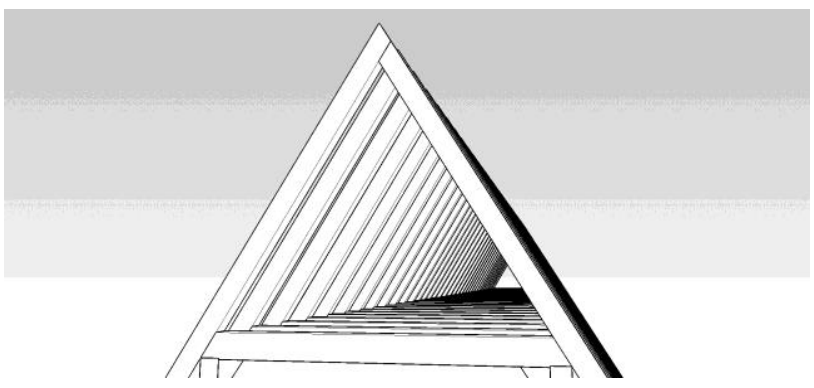

Figures 9b: Details of the $4^{\text {th }}$ level of the framework

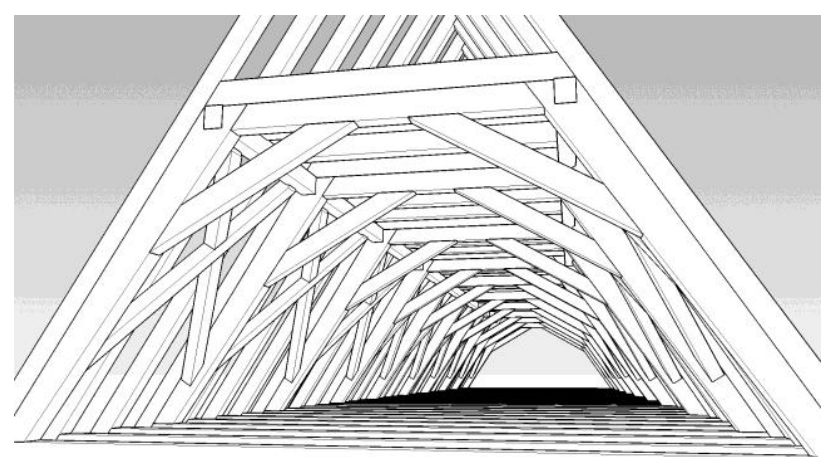

Figures 9c: Details of the $3^{\text {rd }}$ level of the framework

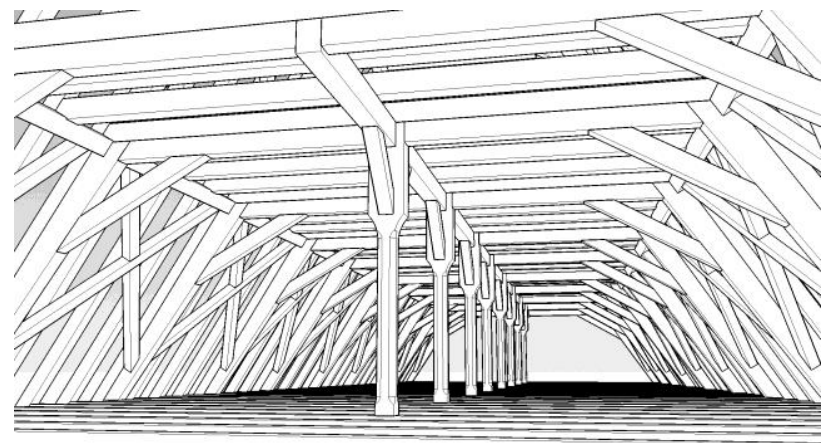

Figures 9d: Details of the $2^{\text {nd }}$ level of the framework

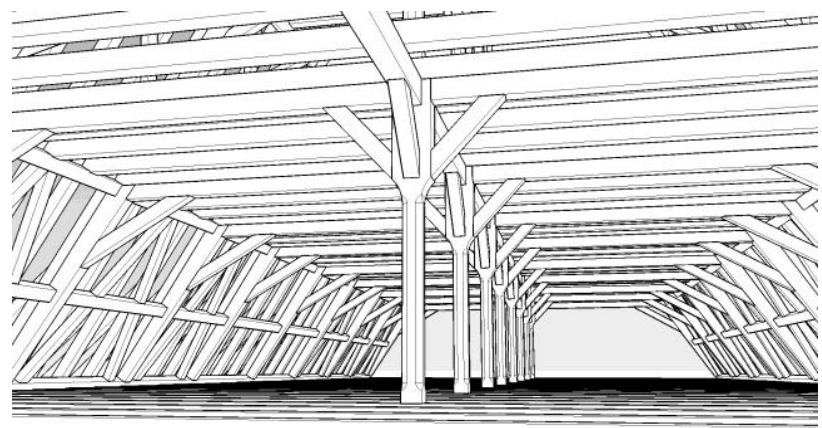

Figures 9e: Details of the $1^{\text {st }}$ level of the framework

\section{STRUCTURING THE MODEL}

The model is structured in layers and coded colour. Each beam is numbered and identified according to its position and function. Identification is then used to associate any type of data in digital form (drawing, photography, mode of assembly, drawing, collecting descriptive report, hyperlink to web page, etc.) to each constitutive element of the framework. Figure 10 shows an example of numbering concept. This numbering for structuring digital data has been used since ancient times. Indeed, the assembly and identification marks were used by carpenters to identify each piece so as to be able to assemble all the pieces on site. 


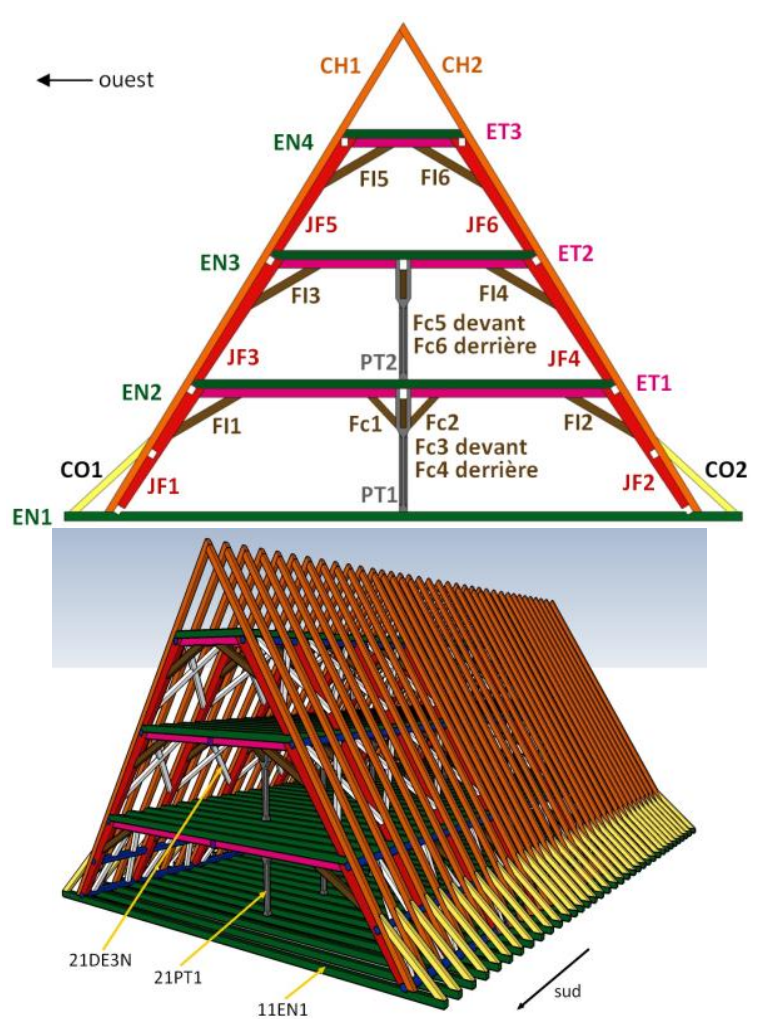

Figure 10: Structure-based numbering

This structure is very important for the case of model integration into a Geographic or Historic Information System (GHIS) especially in 3D-GHIS. The analysis capabilities of 3DGHIS combined with a high performing documentation management system was used here to provide a tool for archiving and documentation, allowing full analysis of the complex structure. Figure 11 shows a result of final modelling by allowing comparison of a modelled framework-portion photograph.

The attic of the current "Seigniory" includes additions compared to its historical constitution, especially as later added chimneys. These chimneys were modelled but will not be included in the historic model of the structure. Figure 12 represents chimney model on the three attic levels. If required, the chimney model can still be incorporated in the whole "Seigniory" model.

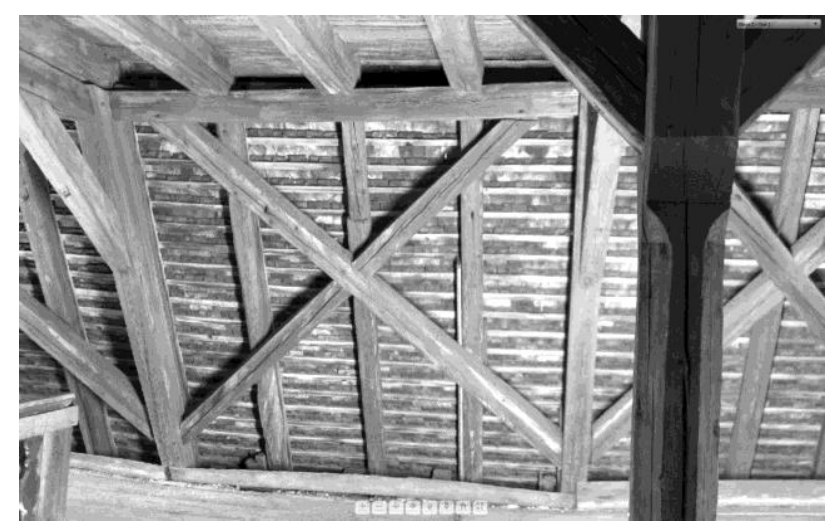

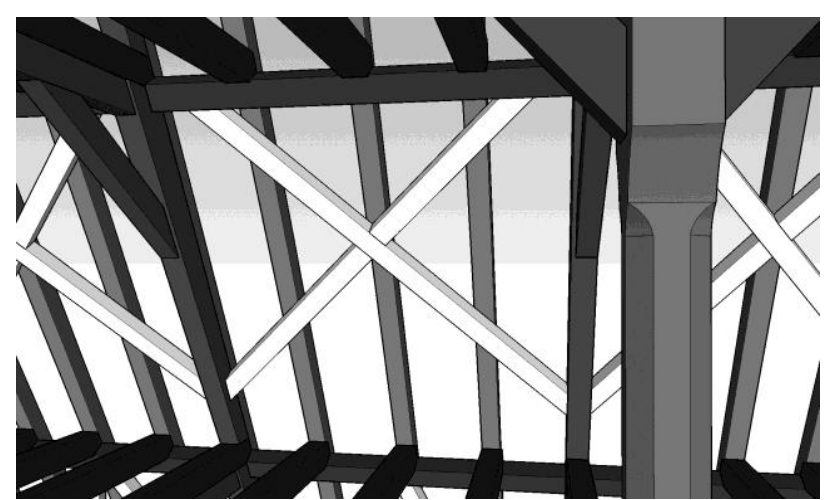

Figure 11: Comparison of view with the actual model

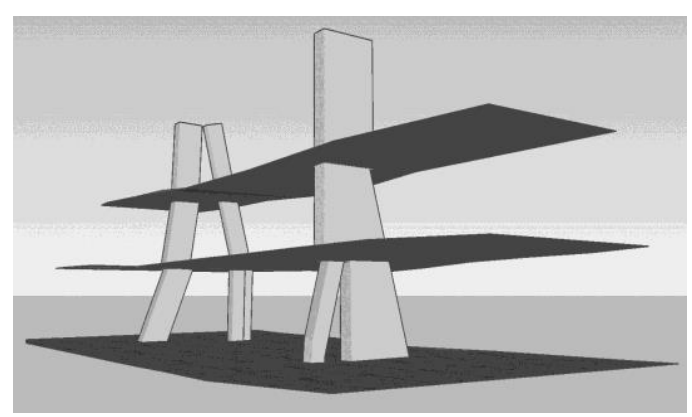

Figure 12: Model of added chimneys

\section{PANORAMIC PHOTOGRAPHY}

Photographs taken with the spherical head will be assembled to create a panoramic image using Autopano Giga software package. Figure 13 shows the different steps for the creation of a panoramic view.

After selecting all the photographs that relate to the same panoramic view, the Autopano Giga automatically generates the first image. In case of $180^{\circ}$ by $360^{\circ}$ panoramic view, the spherical projection is most suitable. The quality of assembly of the panoramic photographs is then checked and adjusted if necessary by the operator's manipulation. The next step is the image processing to standardize the contrasts and colors. The last step is to generate the final panoramic view including all initial co-registered images.

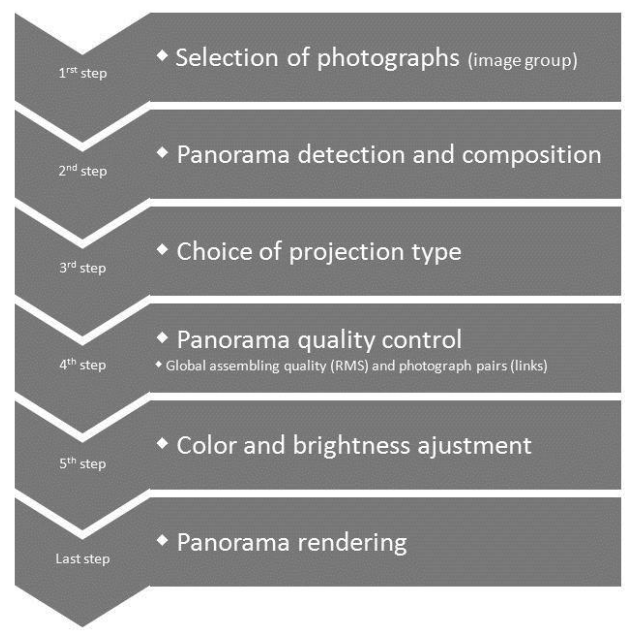

Figure 13: The panoramic photograph creation process by assembling 


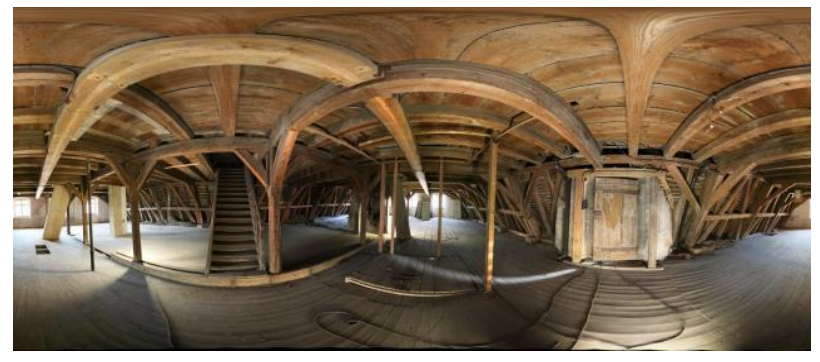

Figure 14: Panoramic view of the first attic level

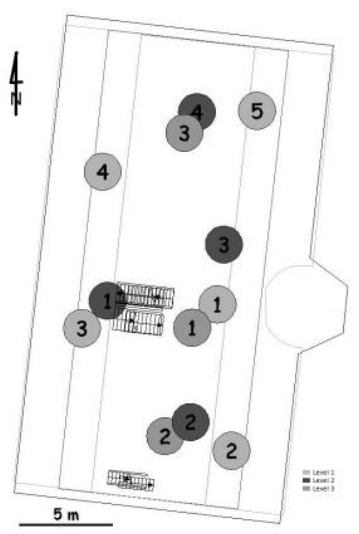

Figure 15: Location of viewpoints for virtual tour.

Figure 14 shows results obtained on the first level of the attic. The combination of panoramic views allows the creation of a virtual tour of the whole attic. Different panoramic views were interconnected via hotspots. The final virtual tour was calculated with Autopano Tour which generates a Flash animation to walk through the panoramic images and passes from one to another using the transitions between hotspots. Figure 15 shows the location of viewpoints, the different levels being fused in the same document. Figure 16 shows an initial view of the virtual tour as well as navigation tools included in the interactive Flash animation.

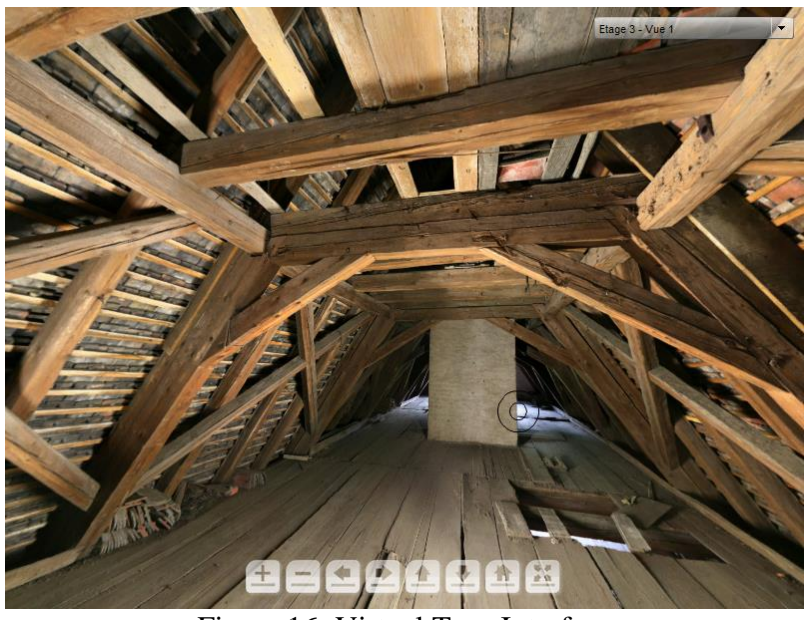

Figure 16: Virtual Tour Interface

This virtual tour is an essential tool for visualization and dissemination of knowledge. Confronted with a specialist of ancient timber frameworks, this virtual tour led to the proposal of a commented course on different levels of the attic. The operator may virtually zoom on every detail of beams to observe the assembly marks, the deformations of the structure, to detect the ancient and reported timbers, etc. As a virtual tool for diagnosis, this visit was very helpful.

\section{CONCLUSION}

This project has studied several approaches in modelling the historic wooden framework of the "Seigniory" of Andlau. 3D geometric modelling of the entire structure was performed including modelling the degree of detail adapted to the needs. A virtual tour whose fineness depends on the number of viewpoints and image resolution was also built. Both offer tools leading to the diagnosis, the understanding of the structure, knowledge dissemination, documentation and the creation of educational activities. The geometric model allows additional measurements in the model for further dimensional analysis or for restoration needs. Figure 17 shows an integration of the modelled framework in a 3D model of the "Seigniory".

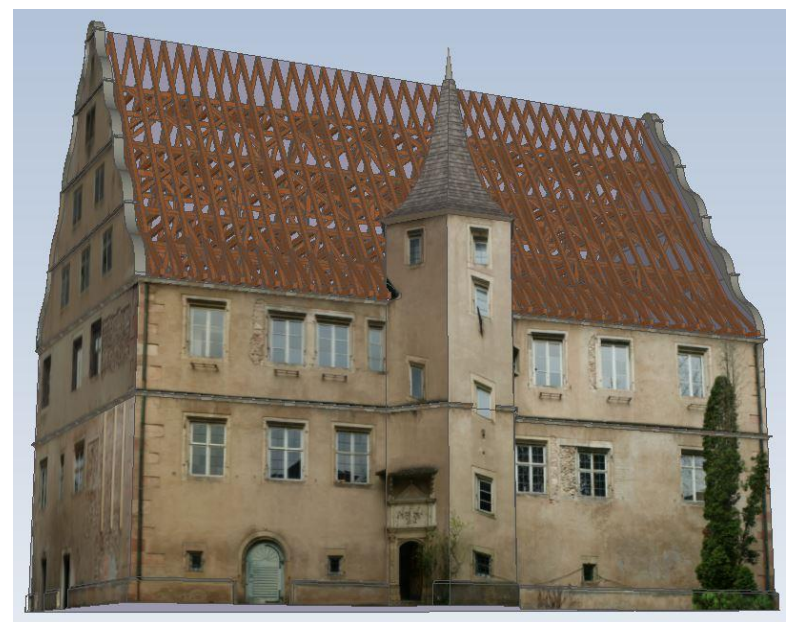

Figure 17: Structured 3D model of the "Seigniory" with accurate model of the wooden framework

\section{PROSPECTS FOR THE USE}

The integration of these measurements in a historical information system will lead to the creation of an interactive model and the creation of a digital visual display unit for consultation. It will be offered to any public to understand interactively the art of constructing a Renaissance structure, with detailed photos, descriptive texts and graphics.

The 3D digital model of the framework will be used directly in the interpretation path, within the space dedicated to "Seigniory" of Andlau.

An interactive touch-screen has been installed. It incorporates several levels of playgrounds (playful, evocative and teaching). In a virtual way, it deals with the different stages of building a wooden framework and clarifies the art of construction.

\section{ACKNOWLEDGEMENTS}

This study was conducted on behalf of and with the support of the Municipalities of the "Communauté des Communes du Piémont de Barr", Alsace, France. 


\section{REFERENCES :}

\section{References from Journals:}

Arias, $\mathrm{P}$, et al. (2005). Close range photogrammetry in heritage monuments documentation. In: Proceedings of the International Workshop "City of Tomorrow and Cultural Heritage Pomerania Outlook", 2005. Gdansk, Poland.

Arias, P, Caamaño, J.C., Lorenzo, H, Armesto, J. (2007). 3D Modeling and Section Properties of Ancient Irregular Timber Structures by Means of Digital Photogrammetry. In: Comp.Aided Civil and Infrastruct. Engineering 22, pp. 597-611.

Autodesk Stitcher (2010). Autodesk ${ }^{\circledR}$ Stitcher ${ }^{\mathrm{TM}}$ Unlimited photo stitching software.

Blersch, D., Balzani, M. and Tampone, G. (2006). The Simulated Timber Structure of the Volumnis' Hypogen in Perugia, Italy. In: Structural Analysis of Historical Constructions, P.B. Lourenço, P. Roca, C. Modena, S. Agrawal (Eds.), New Dehli 2006.

Caamaño, J.C, et al. (2004). Evaluation of roof wood structures from close range photogrammetry data. In: 7th International Conference on Computational Structures Technology, CivilComp Press, Stirling, Scotland, paper 26, 2004. Lisbon, Portugal.

Dawson, P., Levy, R. (2006). Using 3D computer models of Inuits architecture as visualization tools in archaeological interpretation: two case studies from the Canadian Artic.

In: Field Archaeology, 2006, pp. 185-195.

Du, Z., Li, D., Zhu, Y. and Zhu, Q. (2005). 3DGIS-based digital reconstruction and dynamic visualization of timberframe building cluster. In: Proceedings of XXth CIPA Symposium, 27/09-1/10/2005, Torino, Italy.

Fregonese, L. and Taffurelli, L. (2009). 3D model for the documentation of cultural heritage: the wooden domes of St. Mark's Basilica in Venice. In: 3D Arch 2009, 25-28 February 2009, Trento, Italy.

GIM International. (2010). Product survey compare, Terrestrial Laser Scanners, August 2010

http://www.gim-international.com/productsurvey/compare.php

Hoffsummer, P. (2002). Charpentes du XIe au XIXe siècle. Typologie et évolution en France du Nord et en Belgique.

In: coll. Cahiers du patrimoine $n^{\circ} 62$, Paris: Editions du patrimoine, 2002, pp.164-225.

Huang, Y., Ozkaya, I., Krishnamurti, R. (2005). Exploring chinese traditional architecture.

In Proc. CAADRIA 2005, pp. 102-108.

Koehl, M., Viale, A. (2010). Acquisition, modeling and GIS integration of a 3D model of the frame of XVIth century historic building.

In: IAPRS, ISPRS Commission V Mid-Term Symposium 'Close Range Image Measurement Techniques', 21-24 June 2010, Newcastle upon Tyne, UK. pp. 349-354.

Li, D., Hong, T., Zhu, Y. and Yang, J. (2005). 3D reconstruction and simulating assembly of ancient Chinese timber-structure building. In: Proceedings of XXth CIPA Symposium, 27/09-1/10/2005, Torino, Italy

Ling, Z., Ruoming, S. and Keqin, Z. (2007). Rule-based 3D modeling for chinese traditional architecture. In: Proceedings of the $2^{\text {nd }}$ ISPRS International Workshop. 3D-ARCH 2007: "3D Virtual Reconstruction and Visualization of Complex Architectures". ETH Zurich, Switzerland. 4 pages.
Lourenço, P.B., P. Roca, P. (Eds.) (2001). Historical Constructions. In: Guimarães, 2001. pp. 837-846.

Lubowiecka, I., Arias, P. and Armesto, J. (2007). 3D photogrammetric modelling for FEM structural analysis.

Modern Building Materials, Structures and Techniques. In: Proceedings of 9 th International Conference. Vilnius, Lithuania. 2007

Viale, A., (2010). Du relevé à la modélisation de la charpente de la Seigneurie d'Andlau et son intégration dans un système d'information historique.

Engineer diploma thesis, INSA de Strasbourg, 09/2010, 60 pages.

\section{References from Books:}

Chéhu, F. (2003). La photo panoramique. Paris : VM, 2003. ISBN 2-86258-216-6.

Pérouse De Montclos, J.-M. (1989). Principes d'analyse scientifique. Architecture. Vocabulaire.

Paris : Imprimerie nationale, 1989. ISBN 2-11-080961-2.

Valentin, J.-L., (2008)

La charpente, mode d'emploi.

Paris : Eyrolles, 2008. ISBN 978-2-212-12329-6.

\section{References from Websites:}

Communauté de Communes du Piémont de Barr. (2010). Pays de Barr et du Bernstein - Site officiel (France - Alsace Bas-Rhin). http://www.pays-de-barr.fr.

Frich, A. (2013). Arnaud Frich Photographie : photos panoramiques et classiques de Paris, d'églises, de paysages... http://www.arnaudfrichphoto.com/

Google Sketchup 3Dwarehouse (2013)

http://sketchup.google.com/3dwarehouse

Haddlesey, R. (2010). English Late-Medieval timber-framed architecture. http://www.medievalarchitecture.net/

Hugin (2012), Hugin - Panorama photo stitcher http://hugin.sourceforge.net/

Japanese precision, BC Timber frames (2013) http://www.daizen.com/design-3d.php

Kolor. (2013). Image stitching, virtual tour solutions. http://www.kolor.com/

Panavue. (2013).

PanaVue ImageAssembler: digital image stitching system. http://www.panavue.com/

PanoramaFactory. (2013). http://www.panoramafactory.com/

Mathworks. (2012).

Matlab, The Language of Technical Computing.

http://www.mathworks.com/products/matlab/

Photomodeler. (2013). Accurate and Affordable 3D ModelingMeasuring-Scanning. http://www.photomodeler.com/

Trimble Realworks. (2013). Trimble RealWorks software for 3D Scanning in Surveying and Spatial Imaging.

http://www.trimble.com/3D-laser-

scanning/realworks.aspx?dtID=overview\&

Trimble Sketchup, (2013).

$3 D$ modeling for everyone.

http://www.sketchup.com/

Whippie, D. (2013), Timber Frame Design http://www.timberframedesign.net/Index.html 